\title{
História
}

\section{ENTREVISTA COM EvELY BORUCHOVITCH}

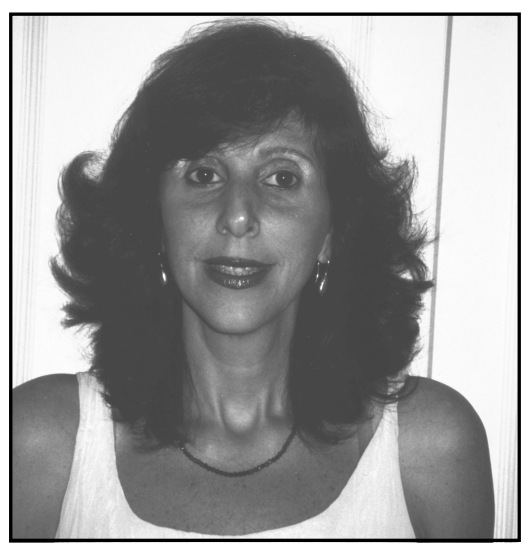

\section{Entrevistadora:KATYALUCIANE DEOLIVEIRA}

EVELY BORUCHOVITCH formou-se em psicologia na Universidade Estadual do Rio de Janeiro (UERJ) e fez seu doutorado na University of Southern California. Evely é professora do ensino superior desde 1995, atua no Programa de Graduação e Pós-Graduação da Universidade Estadual de Campinas, na linha de pesquisa Psicologia, Desenvolvimento Humano e Educação. Sua atuação profissional apresenta grandes realizações, tendo orientado diversos trabalhos de conclusão de curso, dissertações de mestrado e teses de doutorado. Sua trajetória é marcada por inúmeras publicações de livros, artigos e apresentações de trabalhos em congressos nacionais e internacionais. A professora Evely, como é chamada por seus alunos, é uma pessoa dinâmica e engajada com os ideais educacionais brasileiro. Sua competência acadêmica, ética profissional e solicitude, características reconhecidas por seus pares no âmbito da Psicologia Escolar e Educacional, fazem dela uma presença marcante na área. $\mathrm{O}$ relato da entrevista com Evely feita por Katya Luciane de Oliveira revelam tais características no âmbito profissional e pessoal.

\section{Katya: Como foi a sua formação profissional? Evely Boruchovitch:}

Apesar das várias dúvidas e conflitos naturais da adolescência, tinha certeza de que era Psicologia o que eu gostaria de seguir. Eu queria compreender e ajudar o ser humano. Os mistérios da psique e da vida emocional fascinavam-me. Eu prestei o vestibular aos 17 anos para Psicologia e passei para a minha primeira opção que era Universidade Estadual do Rio de Janeiro (UERJ). Tive uma formação teórica e prática bastante sólida e diversificada. Apaixonei-me pela Psicanálise. Como não se encantar? Além de a teoria ser de uma beleza e riqueza ímpares, tive excelentes professores em Psicanálise, como Luís Alfredo Garcia Roza e Maria Luiza Seminério. Ser psicóloga clínica e trabalhar dentro de um referencial psicanalítico era, na ocasião, tudo o que eu mais desejava.

Apaixonada pela psicanálise, percebia que ela não poderia ser acessível a todos. Interessei-me demais pela questão elucidada por Freud, em 1919, no artigo Linhas 
de Progresso na Terapia Psicanalítica, de adaptarmos a nossa técnica às novas condições sociais. Não tinha dúvidas de que era fundamental que profissionais da área de saúde mental refletissem sobre alternativas psicoterápicas ao tratamento psicanalítico, uma vez que este nunca foi acessível à maioria da população brasileira. Envolvi-me, profundamente, com a literatura relativa a psicoterapia breve de orientação psicanalítica. Estagiei no Serviço de Psicologia Aplicada da UERJ, atendendo à adultos, sob a supervisão da Profa. Ana Lúcia Furtado, dentro dessa perspectiva. Pude vivenciar os possíveis desafios do psicólogo clínico. Entretanto, o desejo nítido de ser psicóloga clínica em momento nenhum fez-me fechar os olhos para todos os outros caminhos que a Psicologia poderia me oferecer. Então, realizei estágios nas mais diversas áreas da Psicologia, o que hoje considero ter sido um dos pontos fortes da minha formação. A UERJ oferecia várias possibilidades de prática supervisionada.

Estagiei na área de Psicologia do Trabalho, na Divisão de Desenvolvimento de Pessoal (DDP) da própria UERJ. Atuei em dois projetos importantes, na época: o projeto de implantação de uma creche para os filhos dos funcionários e o projeto de reestruturação de cargos e salários. Ainda na DDP, tive a chance de trabalhar na área de seleção de pessoal, aplicando e levantando testes de aptidão e personalidade, elaborando relatórios de seleção e participando de uma pesquisa sobre grafismo para estudos de seleção. A realização desse estágio não só me permitiu descobrir as atividades do psicólogo do trabalho, mas também representou o despertar do meu interesse pelas atividades de pesquisa.

Queria também ter uma visão mais ampla do papel do psicólogo em outras instituições. Estagiei no Hospital das Clínicas da UERJ, no setor de psiquiatria, fazendo acompanhamento de pacientes psiquiátricos e coordenando grupos operativos com os mesmos. A escola era também uma instituição que muito me instigava. Tive oportunidade de realizar um trabalho de análise institucional, em grupo, sob a supervisão da Marisa Lopes da Rocha, numa escola de uma paróquia, voltada para a alfabetização de adultos de baixa renda. Os estágios - tanto no hospital, quanto na escola - foram bastante enriquecedores e me possibilitaram a descoberta de novas perspectivas de atuação.

Na realidade, não me limitei aos estágios oferecidos pela UERJ. Das atividades fora da UERJ, a que mais me sensibilizou foi a realizada numa instituição situada numa favela e que tinha como objetivo receber crianças e adolescentes do local, no período em que não estivessem na escola, oferecendo-lhes apoio psicopedagógico e orientação profissional. A finalidade era evitar que essas crianças se engajassem, na ausência dos pais, em comportamentos ligados à marginalidade. Cresci bastante nesse estágio, coordenando os grupos de atividades psicopedagógicas para crianças, grupos de informação profissional para adolescentes, e fazendo visitas domiciliares à população da favela que se beneficiava da instituição.

A certeza da importância do ensino de Psicologia na formação de professores conduziu-me a realizar o curso de Licenciatura em Psicologia. A Licenciatura permitiu que eu entendesse mais o sistema educacional brasileiro e seus problemas. A Faculdade de Educação da UERJ me proporcionou uma formação bastante interessante.

Os cinco anos em que estive na UERJ foram caracterizados por inúmeros ganhos, quer profissionais, quer pessoais. Concluí o curso em agosto de 1984 com uma formação teórica sólida e com uma visão bastante ampla da atuação do psicólogo. Além da experiência profissional adquirida, a universidade representou um espaço muito importante para mim, no qual eu aprendi a postular questões complexas e repensar o mundo.

Assim que me formei, trabalhei em consultório particular por quatro anos, realizando atendimento psicoterápico de orientação psicanalítica para adultos e adolescentes, o que muito me gratificava. Tive, concomitantemente, a chance de enriquecer essa prática clínica participando de um projeto de pesquisa em Educação e Saúde, voltado para professores e alunos do ensino fundamental, no Departamento de Biologia da Fundação Oswaldo Cruz (FIOCRUZ), coordenado pela Dra. Virgínia Torres Schall. Tive bolsa de Profissional em Aperfeiçoamento do CNPq. Minha participação nesse projeto diminuía o isolamento da prática clínica, permitia-me atingir um maior número de pessoas e ter uma contribuição profissional mais ampla. Dediquei-me ao estudo da formação de conceitos de saúde e doença em estudantes do ensino fundamental. Temática essa que se constituiu num embrião de uma pesquisa que vim a desenvolver, mais tarde, em maior profundidade, como tese de doutorado.

$\mathrm{Na}$ realidade, eu saí da FIOCRUZ para cursar o doutorado fora do Brasil. Quando ingressei no doutorado na University of Southern California (USC), em Los 
Angeles, pela natureza do meu projeto de pesquisa, a minha área de concentração principal foi Desenvolvimento Humano e a secundária foi Metodologia da Pesquisa.

\section{Katya: Descreva quais aspectos foram mais marcantes no seu doutoramento na University of Southern California. \\ Evely Boruchovitch:}

$\mathrm{Na}$ University of Southern California, eu prestei seleção para o Departamento de Psicologia Educacional da Escola de Educação, visto que pretendia dar continuidade às inquietações que surgiram decorrentes da minha participação no projeto de Educação e Saúde.

Diversos aspectos me marcaram durante o doutorado :

- Era impressionante a quantidade de informações e de leituras que tínhamos a cada aula. O número de referências bibliográficas obrigatórias por disciplina era enorme. Evidentemente, não havia um controle de frequiência, mas ninguém faltava às aulas. As disciplinas eram muito difíceis e a carga de trabalho bastante intensa. Assistir a aulas avançadas em inglês, no início, era doloroso. Os seis anos de curso de inglês no Instituto Brasil-Estados Unidos e três semestres de cadeiras avançadas de Gramática e Literatura do curso de formação de professores não me pouparam das dificuldades iniciais de compreender o inglês falado.

- Como eu era bolsista Capes e a bolsa tinha a duração de quatro anos, tive que fazer um curso de Estatística logo no primeiro semestre, pois ele era pré-requisito de outros. Esse curso era o terror dos americanos. Durante esse curso, ocorreu uma coisa que me marcou muito. Pedi um caderno emprestado para copiar e confirmar as anotações de aula. Ninguém queria me emprestar. Recém-chegada do Brasil, eu não conseguia entender tal comportamento. Até que eu descobri que as avaliações dos cursos lá eram feitas, baseando-se na curva normal, que prefixava o percentual de alunos que poderia tirar uma nota $\mathrm{A}$. Então, se eu acertasse uma questão a mais que alguém, isso diminuía a possibilidade dessa pessoa de tirar a nota máxima. De todas as disciplinas que cursei durante o doutorado, em 99\%, as notas eram dadas dessa forma. Fomentava-se muita competição entre os colegas. Só fiz uma disciplina que todos podiam, a priori, ser "vencedores" (tirar nota A). E isso tudo era extremamente contraditório em relação aos avanços que surgiam, naquela mesma época, acerca das teorias sociocognitivas da motivação, no que concerne à importância dos climas cooperativos em sala de aula para a promoção e manutenção da motivação para aprender do aluno.

- O número de créditos de disciplinas necessárias e obrigatórias para a formação do Ph.D. era bastante elevado. Cursei 66 créditos, o equivalente a 15 disciplinas.

- Havia muita solidão acadêmica. Eu só fiz um trabalho em grupo, durante o curso inteiro. Tinha pouca oportunidade de discussão e interlocução com os colegas.

- A relação era extremamente formal e hierárquica entre professor e aluno, orientador e orientando, e ia se modificando e melhorando à medida que o orientando ia produzindo e avançando nos exames, na tese...

- Havia simultaneidade da seriedade da formação tanto em um nível mais geral, quanto em um nível mais específico.

- A atualização dos textos e da literatura recomendada, ao mesmo tempo que os autores clássicos nunca eram relegados.

- Havia um número excessivo de exames de qualificação. Fiz quatro exames dessa natureza ao longo do curso. O primeiro foi um exame escrito, logo após a conclusão das disciplinas básicas. Após a conclusão de todos os créditos, havia mais três exames: dois escritos, um sobre o estado da arte dos principais temas da sua área de concentração principal e outro sobre o estado da arte dos principais temas da sua área de concentração secundária. O terceiro exame era oral com cinco professores e versava sobre o seu projeto de pesquisa e questões relativas à tese. Esses exames eram longos, estressantes e sem consulta, requerendo um preparo prévio enorme. Defender tese, depois de tudo isso, foi uma das coisas mais tranqüilas do processo.

- Eram rigorosas as críticas nos feedbacks recebidos a cada trabalho corrigido.

- Foi desgastante redigir uma tese em uma língua que não era a minha e lidar com a excelência de redação exigida. $\mathrm{O}$ texto tinha que ter a qualidade do native speaker. No meu caso específico, o inglês não era a primeira língua, nem para mim nem para a minha orientadora, Dr. Birgitte Mednick, que era dinamarquesa.

- Pude me dedicar exclusivamente ao doutorado isso foi muito positivo e único. Até então, eu vivia dividida entre várias atividades.

- Depois da defesa de tese, tive a satisfação de receber alguns reconhecimentos promovidos pela Universidade como: um certificado de Outstanding 
Academic Achievement, a Harold Cook Merit Scholarship, e a Phi Delta Kappa Scholarship.

Katya: Qual o motivo que a levou a escolher a Psicologia Escolar/Educacional como área de atuação?

\section{Evely Boruchovitch:}

Acho que três fatores contribuíram para essa escolha: os dois estágios realizados em Psicologia Escolar durante a graduação, ter sido aluna e ter realizado estágio em Psicologia escolar sob a supervisão da Marisa Lopes da Rocha e ter participado, logo que me formei, de um projeto de pesquisa em Educação e Saúde, na Fundação Oswaldo Cruz.

A participação no projeto de Educação em Saúde representou para mim uma inesgotável fonte de aprendizado e muito contribuiu para o meu amadurecimento profissional e pessoal. Consolidei a certeza de que queria o caminho instigante do mundo da pesquisa e da Psicologia Escolar e Educacional.

Katya: Como se interessou pela Psicologia Cognitiva, em especial a baseada na teoria do processamento da informação? Qual o papel desse referencial teórico na sua atuação?

\section{Evely Boruchovitch:}

Muito preocupada com o fracasso escolar brasileiro, cursei, durante o doutorado, diversas cadeiras fora das minhas áreas de concentração. Investi muito nos cursos ligados a aprendizagem humana, também, e me fascinei pelas contribuições das teorias cognitivas da aprendizagem e suas frutíferas aplicações na melhoria da aprendizagem e do rendimento escolar de alunos. Encantei-me pelos trabalhos sobre a metacognição as propostas de aprendizagem auto-regulada, a possibilidade de fortalecer a capacidade de aprender do aluno, mediante o ensino de estratégias de aprendizagem, de ensiná-lo a aprender a aprender e, a exercer mais controle e reflexão sobre seu o próprio processo de aprendizagem .

Pensando sobre isso, escrevi dois artigos teóricos. O primeiro, em 1993, foi uma reflexão sobre a metacognição e suas possíveis contribuições para o fracasso escolar brasileiro. Já o outro versava sobre o impacto das variáveis psicológicas no desempenho escolar. Foi por meio desse segundo artigo que conheci o Prof. José Aloyseo Bzuneck. Ele, ao ler o artigo, me enviou uma carta falando dos seus interesses semelhantes de investigação. A partir daí, começamos trabalhos em conjunto.

Na realidade, as recentes contribuições da Psicologia Cognitiva baseada na Teoria do Processamento da Informação têm norteado a minha atuação como professora e pesquisadora. Tenho estudado a aprendizagem de alunos brasileiros, tendo esse referencial teórico.

Comecei a pesquisar as estratégias de aprendizagem e os hábitos de estudos de crianças brasileiras do ensino fundamental, acreditando ser um passo inicial importante para se poder contribuir para fortalecer a capacidade de aprender de nossos alunos, para a prevenção de dificuldades de aprendizagem, bem como para se tentar caminhar em direção a construção de um conhecimento maior sobre como os nossos estudantes estudam e aprendem.

Minhas pesquisas têm se concentrado na identificação das estratégias de aprendizagem utilizadas pelos alunos espontaneamente ou como conseqüência de intervenções psicopedagógica e na análise dos fatores afetivos, motivacionais e demográficos que facilitam ou impedem os alunos de aprender e de se engajar no uso de estratégias de aprendizagem.

Tenho tentado caminhar em direção a um ensino voltado para o desenvolvimento de estratégias de aprendizagem e para a promoção da motivação para aprender nos alunos. Há pesquisadores que defendem a criação de uma cultura que valorize e promova o aprender a aprender, os processos metacognitivos e o desenvolvimento do estudante auto-regulado. Penso que isso é um investimento a longo prazo, que só será alcançado se, houver uma inserção maior das contribuições da psicologia cognitiva baseada na teoria do processamento da informação nos cursos de formação de professores, não só do ponto de vista teórico, mas de forma crítica, auto-reflexiva e, sobretudo, vivencial.

Como se constata a carência de instrumentos nacionais relativos à avaliação psicoeducacional, sobretudo dentro desse referencial teórico, tenho tentado também contribuir para discussão e produção de conhecimentos nessa direção. Participo, atualmente, do Grupo de Trabalho de Avaliação Psicológica da ANPPEP.

Katya: Relate um pouco do seu percurso de pesquisadora e, na sua percepção, quais os impasses enfrentados por um pesquisador no Brasil? 


\section{Evely Boruchovitch:}

O meu trabalho na área de formação de conceitos na FIOCRUZ me suscitou uma série de indagações que tentei responder na minha tese de doutorado. $\mathrm{Na}$ ocasião, eu almejava tanto contribuir para a realidade brasileira, obter informações úteis para a melhoria do ensino de Saúde, como para a implementação de programas preventivos em Educação e Saúde. Defendi tese no final de 1993.

Tendo cumprido os meus objetivos profissionais em Los Angeles, era hora de voltar. Por mais que o Rio de Janeiro, minha terra natal, fosse atraente e mais aconchegante do ponto de vista afetivo, queria algo diferente. Escolhi a Faculdade de Educação da UNICAMP pela sua elevada reputação, que me possibilitaria realizações profissionais. Candidatei-me, então, a uma bolsa de recém-doutor no Departamento de Psicologia Educacional (DEPE) da Faculdade de Educação da UNICAMP. Na ocasião, foi-me solicitado o envio do projeto de pesquisa e o curriculum vitae para que o meu pedido pudesse ser avaliado. Elaborei um projeto voltado para a temática do fracasso escolar, tendo como referencial teórico as contribuições da Psicologia Cognitiva baseada na Teoria do Processamento da Informação. Fiquei muito contente ao receber a resposta positiva do DEPE pela admiração que sentia pelo conjunto de professores pesquisadores que lá realizavam um trabalho destacado, em nível nacional. Isso foi no início de 1995.

No final do ano de 1995, houve uma seleção interna, e tive, portanto, a possibilidade de concorrer a uma vaga de Professor-Assistente-Doutor, com regime de trabalho em tempo parcial. Foi gratificante saber que tinha sido uma das selecionadas. Passei a fazer parte do corpo docente do DEPE a partir de julho de 1996, o que me ampliou as oportunidades de atuação profissional, quer em nível de ensino, quer em nível de pesquisa. Mas era um contrato temporário. Prestei outro concurso público, em 1999 e passei a integrar o quadro permanente da Faculdade de Educação da UNICAMP.

Logo após ter sido oficialmente contratada pela UNICAMP, fui convidada pelo Prof. Fermino F. Sisto a fazer parte do Grupo de Pesquisas e Estudos em Psicopedagogia (Gepesp). Participar desse grupo vem representando para mim uma perspectiva muito interessante de atuação em projetos de pesquisa e atividades grupais.

Como eu era tempo parcial na UNICAMP, O Prof. Fermino, em 1999, sugeriu-me que prestasse uma seleção para atuar no Programa de Pós-Graduação em Educação da Universidade São Francisco, que na época estava tentando a sua consolidação junto à Capes. Foi uma experiência profissional rica na qual comecei a desenvolver uma parceria frutífera com a Profa. Acácia Santos, em função de interesses comuns de trabalho. Começou a ficar pessoalmente difícil conciliar o trabalho em duas instituições e surgiu a oportunidade de eu assumir o regime de dedicação exclusiva na UNICAMP. Acabei optando por isso.

Considero que, esses dez anos de trabalho na Faculdade de Educação da Universidade Estadual de Campinas, tem me proporcionado a oportunidade de contribuir com o ensino de Psicologia nos cursos de formação de professores, formar pesquisadores e atuar em cursos de especialização em Psicopedagia, em nível de extensão, o que para mim representa considerável crescimento profissional e pessoal.

Bom, no que diz respeito aos impasses enfrentados por um pesquisador, no Brasil, penso que há uma escassez de verbas para pesquisa nas áreas humanas, há necessidade de aumento de bolsas de mestrado e doutorado. Faz muita falta o aluno que possa se dedicar exclusivamente à pós-graduação. É difícil administrar verbas de projetos grandes, relatórios de prestação de contas e, em geral, não contar com uma infra-estrutura de apoio que possa auxiliar nessa parte. Há também a dificuldade de fazer pesquisas que sejam mais representativas nacionalmente. É necessário haver uma maior integração entre os pesquisadores que estudam a mesma temática, ou temáticas que se complementam, em nível nacional. Precisa-se fomentar e estimular o estabelecimento de um maior número de intercâmbios interinstitucionais.

Katya: Enquanto professora da UNICAMP, tendo orientado diversas dissertações e teses, qual a sugestão que você daria àqueles que querem seguir uma carreira acadêmica?

\section{Evely Boruchovitch:}

Abraçar a vida acadêmica implica um compromisso que envolve, não só a produção de conhecimento e a formação daqueles que produzirão o conhecimento, futuramente, mas também daqueles que usarão esse conhecimento e atuarão com ele. É essencial que as atividades de pesquisa e docência estejam sempre interligadas.

$\mathrm{Eu}$ remeteria aos interessados em seguir vida acadêmica a Carta aos Jovens, de I. Pavlov, na qual ele 
destaca três atributos essenciais mais gerais que devem ser perseguidos por aqueles que querem fazer ciência: Constância, Modéstia e Paixão. Pavlov destaca também a importância da Discrição, da Paciência e do Esforço.

Eu lembraria a eles que pesquisar é produzir conhecimento. Implica, pois, a aquisição de um conjunto de competências que vão desde o estilo de redação ao conhecimento profundo de teorias, técnicas, métodos, instrumentos, procedimentos de coleta e análise de dados. Esse conhecimento leva um tempo enorme para ser construído e é interminável. Seria interessante que essa construção começasse desde a graduação.

Não resistiria e voltaria a Pavlov para reforçar a importância do exercício e do desenvolvimento da humildade. Apontaria para a importância da ética, da autoreflexão. Despertaria a consciência de que, na vida acadêmica, as nossas idéias são e serão sempre criticadas e que a crítica construtiva dos pares se constitui numa das fontes mais ricas de aprendizagem e fortalecimento profissional. É muito importante saber fazê-la e saber recebê-la. Destacaria também a relevância de se ter uma formação teórica sólida, que não se restrinja ao conhecimento de um único referencial teórico em profundidade. Daí a importância de se aproveitar o máximo dos cursos de graduação e de pós-graduação.

\section{Katya: Quais os principais desafios a serem superados pela Psicologia Escolar/Educacional em nosso país? \\ Evely Boruchovitch:}

Por um lado, acho que a Psicologia Escolar e Educacional passa por um momento muito mais favorável hoje, quando comparado à época em me formei, há 21 anos. Hoje há um interesse muito maior dos estudantes de Psicologia por essa área do que naquela época. A existência de uma associação como a Abrapee tem contribuído muito para isso por meio da promoção de congressos e congregação de profissionais e estudantes interessados na Psicologia Escolar e Educacional, bem como tem nos representado muito bem em instâncias como CRP, CFP, entre outras. A Revista de Psicologia Escolar e Educacional tem sido muito útil, organizando, publicando e divulgando o conhecimento que vem sendo produzido em Psicologia Escolar e Educacional, mostrando o quanto é instigante e interessante o seu objeto de estudo.
Por outro lado, acho que a formação do psicólogo escolar ainda deixa muito a desejar. Ele acaba por não ter uma idéia de todas as possibilidades de atuação que se pode ter além da escola. Tenho atuado em cursos de especialização em Psicopedagogia. Constata-se que a formação do psicólogo é precária em Psicologia Escolar e Educacional, bem como em Educação. O mesmo ocorre com o pedagogo que também carece dos conhecimentos acerca das contribuições da Psicologia para a Educação.

A Psicologia Escolar e Educacional deve ajudar os professores a maximizar as condições que favoreçam a aprendizagem e a motivação para aprender do aluno. Deve se preocupar também com a promoção da saúde mental, do bem-estar emocional, do desenvolvimento pleno e da qualidade de vida daqueles que aprendem e ensinam. Ainda temos um enfoque muito remediativo. Inexiste uma cultura da prevenção.

É inegável que tenhamos hoje uma literatura considerável e importantíssima sobre o fracasso escolar e problemas educacionais brasileiros, mas temos pouca produção nacional sobre o que promove a aprendizagem dos nossos alunos.

Os livros de Psicologia Educacional precisam ser mais voltados para a aplicação do conhecimento.

Embora o panorama esteja se modificando e vários esforços estejam sendo empreendidos, carecemos ainda de instrumentos de avaliação psicoeducacional nacionais e/ou validados para nossa realidade.

Deveria haver uma maior interação entre pesquisadores. Há uma dificuldade de se caminhar em direção a construção de um corpo de conhecimento mais mais compreensivo da aprendizagem de nossos alunos, que possa inclusive nortear melhor a formação de professores.

Falta também uma maior aproximação daqueles que fazem e produzem psicologia escolar na sala de aula, na escola, sobre o professor, sobre o aluno, com aqueles que atuam no delineamento de políticas nacionais de Educação, de Saúde.

Eu gostaria muito de agradecer à Revista Psicologia Educacional e Escolar pela oportunidade de participar desta entrevista e refletir sobre essas questões. 